\title{
ENSINO EM DIREITOS HUMANOS: Considerações no Contexto da Prática
}

\author{
Jean Mac Cole Tavares Santos ${ }^{1}$ \\ Suzana Paula de Oliveira Pereira²
}

\begin{abstract}
RESUMO
Neste artigo discutimos o ensino de direitos humanos no Ensino Médio relacionando os instrumentos legais com as ressignificações dos docentes no contexto da prática. Na metodologia, partimos da análise documental dos principais instrumentos legais que norteiam o tema para embasar a perspectiva de política em ensino de direitos humanos em vigor nas escolas. A seguir, com entrevistas com docentes da escola pública, buscamos verificar a ressignificação de tal política na escola. Tomamos como referência a teoria do discurso de Laclau (2006) e o ciclo contínuo de políticas de Ball (2011), reconhecendo que as ressignificações acontecem diante de múltiplos contextos de forma descentrada, aproximando discussões sobre igualdade e diferença na escola. Os resultados obtidos concluem que os discursos oficiais sofrem ressignificações ligadas aos interesses e disputas políticas inerentes ao contexto da prática. Assim, é na escola, na atuação docente, que o ensino dos direitos humanos ganha sentidos, sempre como resultados de múltiplas disputas.
\end{abstract}

Palavras-chave: Direitos humanos. Escola pública. Ensino Médio.

\section{TEACHING IN HUMAN RIGHTS: CONSIDERATIONS ON THE CONTEXT OF PRACTICE}

\begin{abstract}
This article brings a discussion about the teaching of human rights in secondary education relating the legal instruments with the teachers' resignifications on the context of practice. Methodologically speaking, a documental analysis of the main legal instruments that guide the theme was carried out to support the policy's perspective in human rights' teaching existing in schools. Then, through interviews with public school teachers, we intended to verify the resignification of such policy in the school. Laclau's discourse theory (2006) and Ball's continuous policy cycle (2011) were part of our theoretical framework, acknowledging that resignifications take place in multiple contexts, in a descentralized way, bringing closer discussions about equality and differences in school. The findings showed that the official discourses go through resignifications that are connected to the interests and political disputes inherent to the context of practice. Thus, it is at school, through the teachers' work, that the human rights' teaching gain meanings, always as a result of multiple disputes.

Keywords: Human rights. Public school. Secondary education.
\end{abstract}

RECEBIDO EM: 26/6/2017

ACEITO EM: 24/10/2017

\footnotetext{
${ }^{1}$ Graduação em História (Licenciatura) pela Universidade Estadual do Ceará (Uece, 1995). Especialização em Teoria e Metodologia da História pela Universidade Estadual Vale do Acaraú (UVA, 1997). Mestrado em História Social pela Universidade Federal do Rio de Janeiro (UFRJ, 2000). Doutorado em Educação pela Universidade Federal da Paraíba (UFPB, 2007), com estágio doutoral na Universidade de Valência (UV - Valência, Espanha), e Pós-Doutorado no Programa de Pós-Graduação em Educação (Proped) na Universidade do Estado do Rio de Janeiro (Uerj), com bolsa do Conselho Nacional de Desenvolvimento Científico e Tecnológico (CNPq), sob a supervisão de Alice Casimiro Lopes. É professor-adjunto 4 do curso de Pedagogia, Faculdade de Educação, Universidade do Estado do Rio Grande do Norte (Uern). É coordenador do Grupo de Pesquisa Contexto e Educação (Uern/CNPq). Coordena, ainda, pesquisas sobre o mundo do trabalho e a formação escolar no Ensino Médio nos Estados do Rio Grande do Norte e Ceará com apoio do CNPQ, da Fapern e da Funcap. Participa também do projeto de extensão "Laboratório de Estudos e Pesquisas em Paulo Freire e Educação Popular" (Lefreire) na Uern e coordena o Projeto de Extensão Estudos em Indisciplina e Violência na Escola (Eive), na Faculdade de Educação/Uern. Foi tutor do PET Pedagogia Uern, entre dezembro de 2010 e Janeiro de 2013. maccolle@hotmail.com

${ }^{2}$ Mestre em Ensino pela Universidade do Estado do Rio Grande do Norte (2018). Especialista em Direitos Humanos pela Universidade do Estado do Rio Grande do Norte (2009). Graduada em Direito pela Universidade do Estado do Rio Grande do Norte (2007). Atualmente é professora e servidora pública. Participa do Grupo de Estudos e Pesquisas Contexto e Educação (UERN/CNPq) e do Projeto de Extensão Estudos em Indisciplina e Violência na Escola (Eive) na Faculdade de Educação/UERN. suzanaoliveira.advogada@gmail.com
} 
Tratamos neste artigo acerca do ensino de direitos humanos, tendo como referência uma escola da cidade de Mossoró, no Estado do Rio Grande do Norte-RN. Consideramos os diversos sentidos atribuídos à expressão direitos humanos, buscando perceber como se dá o seu ensino de forma interdisciplinar. Interessa-nos entender como os docentes respondem às exigências e expectativas propostas nos instrumentos legais nacionais relacionados ao ensino desta temática, principalmente no que diz respeito ao seu caráter interdisciplinar, assim como em relação à ressignificação das questões apontadas nos documentos oficiais como referentes ao tema.

O Ensino Médio, como última etapa da educação básica, pode ser considerado uma fase na qual o discente poderá arraigar seus valores e conduta no sentido de formar uma visão independente acerca dos direitos humanos. A inclusão da discussão a respeito destes direitos mostra-se, pois, de grande relevância para o Ensino Médio, considerando que os discentes estão em fase de decisões importantes na vida, seja no sentido de admissão no mundo do trabalho, seja na contínua inserção em ambientes de socialização, necessitando assim adquirir conhecimentos imprescindíveis para ter uma visão autônoma e ao mesmo tempo crítica da sociedade (SILVA; TAVARES, 2012).

$O$ ensino em direitos humanos insere-se num contexto interdisciplinar do processo de aquisição de conhecimento, estando interligado por diferentes práticas pedagógicas, sendo permeado pelas diversas ressignificações no contexto da prática.

Entendemos o contexto como uma série de movimentos em que escola está envolvida, bem como está relacionado à reformulação de sentidos globais e locais, considerando os órgãos governamentais, a comunidade escolar e a própria escola como agentes dessa dinâmica e constante construção de sentidos (SANTOS; OLIVEIRA, 2013).

Nesse sentido o foco principal deste trabalho é perceber como se dá o ensino de direitos humanos nas escolas públicas de Ensino Médio no contexto da prática.

\section{A PESQUISA EM FOCO}

A pesquisa, de natureza qualitativa, traz aspectos metodológicos de natureza exploratória e descritiva. Inicialmente foi feito levantamento documental e bibliográfico dos principais documentos voltados para o ensino em direitos humanos no Ensino Médio; a seguir foi realizada entrevista com docentes numa escola pública estadual de Ensino Médio da cidade de Mossoró-RN. Desse modo, para análise do tema utilizamos documentos oficiais, fazendo um percurso histórico dos principais regramentos relacionados ao ensino desta temática. Consideramos a Constituição Federal de 1988 como marco inicial, passando pela Lei de Diretrizes e Bases (LDB), Parâmetros Curriculares Nacionais (PCNs), Orientações Educacionais Complementares ( $\mathrm{PCN}+)$, Orientações Curriculares do Ensino Médio (OCEMs), Plano Nacional de Direitos Humanos (PNDH-3), Plano Nacional de Educação em Direitos Humanos (PNEDH), Diretrizes Nacionais para a Educação em Direitos Humanos (DNEDH) e Plano Estadual de Educação do Rio Grande do Norte (PNERN). De forma geral, vimos que tais documentos apontam para assuntos relacionados aos direitos humanos, basicamente visando a superar o racismo, a homo- 
fobia, os preconceitos de gênero, a xenofobia, a intolerância religiosa, buscando ainda a garantia do acesso à educação de maneira universal e inclusiva, entre vários outros fatores.

Neste sentido, com o objetivo de perceber como se dá a relação entre os instrumentos legais e o ensino de direitos humanos nas escolas públicas de Ensino Médio no contexto da prática, realizamos uma aproximação com docentes de uma escola estadual, localizada na zona urbana da cidade de Mossoró, no Estado do Rio Grande do Norte, por meio da utilização de entrevista com roteiro semiestruturado. A seleção da instituição foi baseada na percepção social da importância dada ao ensino destes direitos na escola.

Para a entrevista selecionamos docentes experientes, com atuação significativa na escola, envolvidos nas atividades pedagógicas propostas pelo núcleo gestor e com interesse pela pauta pesquisada. Dessa forma, foram selecionados três professores que mais se aproximavam dos seguintes critérios: 1- Cada professor atuar em áreas distintas de ensino; 2- Ser professor nos três anos do Ensino Médio; 3- Ser professor concursado de escola pública de Ensino Médio que tenha permanência mínima de três anos de docência na escola; 4- Que expresse o desejo de contribuir com a nossa pesquisa.

Na primeira parte da entrevista foi traçado o perfil dos professores entrevistados, ${ }^{3}$ buscando conhecer os sujeitos a partir de dados como área de interesse, disciplina e tempo de atuação profissional. O professor $A$, sexo masculino, ensina a disciplina de Ciências, com 6 anos de conclusão do curso e igual período de atuação, podendo ser considerado novo na profissão docente. A professora B, sexo feminino, ensina a disciplina de Literatura, com 30 anos de conclusão de curso e 29 anos de atuação. O professor C, sexo masculino, ensina a disciplina de História, com 25 anos de conclusão e 3,5 anos de atuação, podendo ser considerado novo na profissão docente. Foi possível perceber a distância de mais de 24 anos de diferença entre o professor com a formação mais antiga e a mais recente, o que pode indicar lenta renovação do quadro de docentes, bem como possibilita a troca de experiências e construção de saberes a partir de pontos de vista distintos.

Para entendemos os principais significados da expressão direitos humanos, utilizamos os conceitos de Santos e Oliveira (2013), ao discutir o caráter universalista da acepção dos direitos humanos. No sentido de romper com uma suposta visão universalista do conceito, utilizamos a perspectiva de descentramento e da não fixação de sentidos, defendida por Lopes e Macedo (2011a). Já com Ramos (2011) fundamentamos o sentido de direitos humanos a partir da referência na discussão da igualdade e da diferença.

\section{DIREITOS HUMANOS: Noções Introdutórias}

Antes de adentrar nas discussões acerca do ensino dessa temática, elegemos contingencialmente o sentido de direitos humanos, de modo que essa significação sirva de referência, mesmo que não de forma centrada, dentro do texto.

3 Os nomes dos professores foram substituídos por letras, " $A$ ", " $B$ ", " $C$ ", no intuito de preservar o seu anonimato. 
Uma das principais acepções refere-se a um caráter hegemônico e universal. Uma das características principais atribuídas aos direitos humanos, portanto, é o seu caráter universal no sentido de representar um entendimento comum a todos os povos. Santos e Oliveira (2013) argumentam que esses direitos podem ser considerados como

universalmente válidos independentemente do contexto social, político e cultural em que operam e dos diferentes regimes de direitos humanos existentes em diferentes regiões do mundo. [...] Partem de uma concepção de natureza não humana; o que conta como violação de direitos humanos é definido pelas declarações universais, instituições multilaterais e organizações não governamentais (p. 54).

Percebemos, com os autores citados, o caráter incontestável da hegemonia destes direitos como linguagem de dignidade humana. Tal concepção, porém, denuncia uma preocupante uniformidade da realidade, entendendo, a priori, que o discurso seria efetivado para todos os seres humanos. Nesse sentido, os autores aprofundam a reflexão: Será a hegemonia de que goza hoje o discurso dos direitos humanos resultado de uma vitória histórica, ou pelo contrário, de uma derrota histórica? (SANTOS; OLIVEIRA, 2013, p. 42). Para eles, a discrepância se dá quando se reconhece a existência de direitos considerados naturais e inerentes a qualquer ser humano, porém a luta por tais direitos resume-se à sociedade ocidental, olvidando uma parcela significativa da população mundial que não tem força para hegemonizar suas demandas. Dessa maneira, o questionamento trazido pelos autores põe em xeque a visão hegemônica citada, de modo a obrigá-los a problematizar se a mencionada hegemonia está sendo dissipada pelos inúmeros fatores e disputas que constituem o conceito em discussão.

Reforçando a discussão, concordamos com Ramos (2011) ao considerar essa universalidade mitigada, à medida que o valor universal corresponde à significação cristã ocidental de dignidade humana, sendo tal universalidade apenas um reflexo de uma visão eurocentrista e excludente, que não considera diversas nações como sujeitos de direitos. Acerca da discussão da necessidade de reconhecer os direitos humanos como universais, temos que

significa anular a pluralidade de sentidos sobre a vida, dignidade, composição da família e relação familiar, morte, justiça e liberdade, entre outros, presentes em diferentes localidades. Implica anular as diferenças e ignorar a produção de novos significados possibilitados pelas hibridações culturais que o mundo globalizado intensifica (RAMOS, 2011, p. 41).

Nesse sentido, uma abordagem universalista/totalizante do real não considera as disputas que ocorrem nos diferentes contextos. Ao destacar a dificuldade em se chegar numa concepção contemporânea de direitos humanos de modo a contemplar as populações asiáticas, africanas e ameríndias, bem como os fenômenos da globalização e do multiculturalismo, a autora rechaça a possibilidade de centralismo do conceito, apostando em perceber sua dinamização no contexto de tal modo que vai sendo usado/ gerado, tendo sua significação relacionada aos usos culturais diversos. A tônica das relações de igualdade e da diferença, trazida por Ramos (2011), orienta o exercício de busca de outra acepção, reconhecendo como conceito em constante construção. 
Assim, a disputa pelo reconhecimento das diferenças, ressaltamos, é resultado da articulação de diversos grupos que buscam a hegemonização de suas demandas, seja no combate ao racismo, homofobia, preconceitos de gênero, xenofobia, seja nas diversas discussões que se aproximam do conceito que entendemos como articulador de demandas em disputas. Tais disputas, de forma diversa, acabam por provocar o sentido de direitos humanos, influenciando na criação de leis, normas, diretrizes, etc. As ações afirmativas, como o uso de cotas em concursos públicos, por exemplo, acabam por representar interesses de determinados grupos, forçando o sentido de direitos humanos para dar conta de diferenças como raça, etnia, origem social, nível de renda, nível de escolaridade, entre outros. Aqui, sem muito esforço, percebemos que o particular pode assumir função importante no conceito universalizante desses direitos. Por mais, no entanto, que essa interpretação apresente elementos que promovam uma aproximação conceitual mais ampla que a universalista, é necessário considerar o risco de cair em binarismos, conceituando simplesmente pela ideia de uma suposta identidade, tomando esta como diferença (LOPES; MACEDO, 2011b).

Acerca da identidade e da diferença, Lopes e Macedo (2011b, p. 223) questionam o conceito de identidade ao afirmar que "as identidades são definidas pela sua diferença em relação a outras identidades e não por algo que the és próprio". A diferença, portanto, como aquilo que possibilita a distinção, respeita/constrói as definições sem tentar homogeneizar as relações e os sentidos que escapam ao padronizado. Esta acepção não centrada pode ser levada para o campo dos direitos humanos e auxiliar no entendimento pelo qual pode ser considerado como um significante vazio ${ }^{4}$ (LOPES; MACEDO, 2011B; RAMOS, 2011), tendo em vista que seu preenchimento pode mudar de acordo com o contexto.

Nessa perspectiva, um determinado significado pode ser hegemônico, reconhecendo o caráter provisório dessa hegemonia. Neste sentido, Laclau (2006) entende que o processo hegemônico ocorre por meio do discurso de sujeitos descentrados em sociedades não fixadas, nas quais perpassam constantes negociações de sentidos dotados de transitoriedade, desprovidos de uma plenitude discursiva que defina, de forma imutável, os sentidos das coisas. O reconhecimento da impossibilidade dessa totalidade discursiva auxilia no entendimento de que os conceitos vão se constituindo a partir de significantes vazios, preenchidos provisoriamente pelos diversos elementos que envolvem o processo articulatório, de modo que um mesmo significante possa estar associado a diferentes significados em contextos distintos (LACLAU, 2006). Partindo desta ideia de que não existe sujeito fixo, Lopes e Macedo (2011b) destaca:

As identidades são o resultado de um processo de identificação no qual os indivíduos se subjetivam dentro dos discursos culturais. [...]. As identidades nomeadas talvez pudessem ser mais bem descritas como fixação de identificações contingentes dos sujeitos, que ocorrem em circunstâncias muito próprias (p. 224).

\footnotetext{
${ }^{4}$ De acordo com Lopes (2010) inspirada nos estudos de Laclau, o significante vazio relaciona-se com aquilo que todos se identificam pelas suas articulações, são as várias concepções que estão inseridas em uma agenda política. Isso ao mesmo tempo que cria muitas possibilidades e entendimentos, acaba por não ter uma definição que possa torná-lo um discurso hegemônico.
} 
Com Lopes e Macedo (2011b), entendemos as fixações como provisórias e precárias, não havendo identidades fixas, mas identificações contingentes, construídas nas dinâmicas das disputas no contexto social/histórico.

Com esse entendimento adotamos, no presente artigo, a compreensão de que o conceito de direitos humanos está em constante disputa; igualmente, a figura do sujeito de direitos não é fixa, podendo mudar de acordo com o contexto. Defendemos tal visão no sentido de ser a que mais se adéqua ao dinâmico contexto da prática, aproximando-se com a nossa ideia de não fixação de sentidos para conceituar estes direitos. CompartiIhamos do entendimento de que a concepção de direitos humanos pode corresponder a um significante vazio, ${ }^{5}$ sempre a ser preenchido, contingencialmente, por demandas que refletem os interesses de um determinado grupo e que se hegemonizam de acordo com os contextos em disputas.

De maneira ampla, sobre a produção de políticas educacionais, dialogamos com o Ciclo Contínuo de Políticas de Ball e Mainardes (2011). ${ }^{6}$ Considerando especificamente o objetivo deste texto, o de relacionar a legislação vigente com a prática em sala de aula, entendemos relevante dialogar mais proximamente com o contexto de produção de textos e o contexto da prática. Como apresentado por Ball e Bowe (1998), o contexto de produção dos textos está relacionado ao momento em que são discutidas as possibilidades de escrita de documentos que pretendem induzir políticas curriculares, momento, então, privilegiado, em que as políticas são inseridas nos documentos; o contexto da prática, assim, pode ser considerado o local, também privilegiado, em que as políticas são ressignificadas, readaptadas, hibridizadas, "puestas en practica", a partir de suas próprias disputas e interesses locais. Ademais, importa mencionar que tais contextos não correspondem a fases ou etapas separadas, estanques, coexistindo e se completando mutuamente.

A produção de políticas envolve processos dinâmicos que são influenciados por interesses em diversos níveis e com diferentes profundidades. Não se trata, portanto, de algo produzido em uma esfera (normalmente governamental) para ser posto em prática em outra (normalmente na escola). Nessa perspectiva, buscaremos compreender como ocorre o ensino de direitos humanos na escola.

\section{INSTRUMENTOS LEGAIS NACIONAIS E O ENSINO DE DIREITOS HUMANOS}

Neste tópico buscaremos, sucintamente, apontar a construção de indicadores de direitos humanos nos documentos legais que nas últimas décadas influenciam/influenciaram a prática nas escolas.

\footnotetext{
De acordo com Laclau, significante vazio sustenta que quanto mais ampla certa cadeia de equivalência for, menos a demanda que assume a responsabilidade de representá-la como um todo vai possuir um laço estrito com aquilo que constituía originariamente como particularidade, quer dizer, para ter a função de representação universal, a demanda vai ter de se despojar de seu conteúdo preciso e concreto, afastando-se da relação com seu(s) significado(s) específico(s), transformando-se em um significante puro que é o que conceitua como sendo um significante vazio (LACLAU, 2005, p. 3).

${ }^{6}$ A respeito dos contextos adotamos o ciclo contínuo de políticas de Ball e Bowe (1998), destacando os três contextos principais: o contexto de influência, o contexto da produção do texto e o contexto da prática. Para mais informações ver: Ball e Mainardes (2011), Ball e Bowe (1998), Lopes e Macedo (2011b) e Santos e Oliveira (2013).
} 
No Brasil, o regime instituído pela ditadura militar, de 1964 a 1985, representou período histórico de violações a direitos, atualmente considerados fundamentais (RAMOS, 2011). A reação, posterior ao período ditatorial, ensejou um movimento em prol da construção de uma Constituição repleta de dispositivos garantidores dos direitos fundamentais. A Constituição Federal de 1988, assim, trouxe em seu bojo disposições acerca do direito à educação, inseriu princípios relacionados a estes direitos e deu status constitucional aos tratados internacionais dessa área, trazendo ainda diversas disposições acerca dos direitos fundamentais.

Na década de 90, sob a chamada Constituição Cidadã, os movimentos em prol dos direitos humanos influíram na formatação da Lei de Diretrizes e Bases da Educação (LDB), que dispõe acerca da educação básica e sua subdivisão em Ensino Fundamental e Médio, este último o foco deste trabalho (BRASIL, 1996). A LDB trouxe alguns princípios dos direitos humanos, tais como o artigo 30 , focando em princípios como a igualdade de condições para o acesso e permanência na escola, a livre- escolha para aprender, ensinar, pesquisar e divulgar a cultura, o pensamento, a arte e o saber. Corrobora, então, com o pluralismo de ideias e de concepções pedagógicas no sentido de promover o respeito à liberdade e o apreço à tolerância. Tais princípios possuem forte relação com o ensino desta temática, haja vista que a prática da tolerância, a busca da igualdade e demais princípios estão inseridos nas discussões consideradas inerentes ao tema.

Os primeiros Parâmetros Curriculares Nacionais (PCNs) foram criados em 1996, voltados para o Ensino Fundamental, na tentativa de universalizar/direcionar a abordagem das disciplinas, e conforme Santos e Chauí (2013), inseriram discussões voltadas para a ética e a cidadania, palavras-chave para os direitos humanos. Já nos Parâmetros Curriculares Nacionais para o Ensino Médio (PCNEM) do ano 2000, foram inseridas disposições acerca da política de igualdade e bases legais que orientam sobre a adoção destes direitos e o exercício dos direitos e deveres da cidadania como elemento que direciona para a vida civil. Percebe-se, de forma geral, a acepção de cidadania como sinônimo de direitos humanos, visando, quase sempre, a combater e superar exclusões, diferenças, preconceitos, etc., assumindo caráter transformador da sociedade.

No ano de 2002, com as Orientações Educacionais Complementares aos Parâmetros Curriculares Nacionais do Ensino Médio (conhecidas nas escolas como PCN+), as referências a direitos humanos, principalmente na área de Ciências Humanas e suas Tecnologias, dentro do eixo temático de História (BRASIL, 2002), vem com a sugestão "cidadania: diferença e desigualdades", trazendo em seu conteúdo a Declaração Universal de Direitos Humanos. Nas mesmas Orientações, nos conceitos estruturadores da disciplina de Sociologia, estes direitos são citados como princípios e valores universais a serem trabalhados, visando a combater as desigualdades presentes na sociedade atual.

Sobre as "ações afirmativas", especificamente, a Lei 10.639/2003 obriga a inclusão no currículo oficial da rede o ensino de conteúdos que tratam da história e cultura afro-brasileira nos currículos da Educação Básica. Tais disposições ganham mais destaque ainda com a Lei 11.645/2008, que traz também a inclusão da cultura/história indígena como tópico a ser estudado nos currículos da Educação Básica. As duas leis, além de 
representarem uma conquista de grupos que buscam o reconhecimento do papel dos negros e indígenas na cultura nacional, fomentam a caracterização da ideia de inclusão, diferença e minorias na concepção destes direitos.

A análise destes primeiros textos legais contribuiu para identificar a descoberta de palavras-chave que dão sentidos ao significante direitos humanos, tais como cidadania, tolerância, igualdade, diferença, inclusão e liberdade religiosa.

Nesse sentido, faz-se necessário buscar a possível fixação destas palavras-chave nos documentos nacionais posteriores, bem como identificar novos significados que preenchem os conceitos dos direitos humanos.

\section{Instrumentos Legais Nacionais Específicos para o Ensino de Direitos Humanos}

A criação de novos documentos nacionais representa um progresso significativo no ensino nessa área, tendo em vista que inseriu diversos dispositivos asseguradores para a promoção, execução e consolidação da referida questão, demonstrando a disputa pela hegemonização do ensino desse conteúdo.

\begin{tabular}{|c|c|}
\hline \multicolumn{2}{|c|}{ PRINCIPAIS DOCUMENTOS REFERENTES AO ENSINO DE DIREITOS HUMANOS } \\
\hline Norma & TEMA \\
\hline A Constituição Federal de 1988 & $\begin{array}{l}\text { Dispõe acerca dos direitos humanos e direitos à educação, } \\
\text { bem como traz todos os princípios que norteiam os demais } \\
\text { documentos nacionais. }\end{array}$ \\
\hline Lei 9.394/1996 & Dispõe acerca das Diretrizes e Bases da Educação. \\
\hline PCNEM, 2000 & Parâmetros Curriculares Nacionais para o Ensino Médio \\
\hline OEC - PCNEM, 2002 & $\begin{array}{l}\text { Orientações educacionais complementares aos Parâmetros } \\
\text { Curriculares Nacionais do Ensino Médio de } 2002\end{array}$ \\
\hline Decreto no $5.296 / 2004$ & $\begin{array}{l}\text { Trata da acessibilidade e da garantia dos recursos didáticos } \\
\text { e pedagógicos para atender às necessidades educativas } \\
\text { especiais. }\end{array}$ \\
\hline OCN - 2006 & $\begin{array}{l}\text { Trata das Orientações Curriculares Nacionais para o Ensino } \\
\text { Médio. }\end{array}$ \\
\hline Lei $11.645 / 2008$ & $\begin{array}{l}\text { Trata da inclusão, no currículo oficial da rede de ensino, da } \\
\text { obrigatoriedade da temática história e cultura afro-brasileira } \\
\text { e indígena nos currículos a educação básica. }\end{array}$ \\
\hline Decreto no $7.037 / 2009$ & Trata do Programa Nacional de Direitos Humanos - PNDH-3. \\
\hline Parecer CNE/CEB № 7/2010 & $\begin{array}{l}\text { Tratam das Diretrizes Curriculares Nacionais para a Educação } \\
\text { Básica. }\end{array}$ \\
\hline $\begin{array}{l}\text { Parecer CNE/CEB no 5/2011 e da resolução } \\
\text { CNE/CEB no 2/2012 }\end{array}$ & $\begin{array}{l}\text { Tratam das Diretrizes Curriculares Nacionais para o Ensino } \\
\text { Médio. }\end{array}$ \\
\hline $\begin{array}{l}\text { Parecer CNE/CP n. 8/2012, e Resolução } \\
\text { CNE/CP n. } 01 / 2012\end{array}$ & $\begin{array}{l}\text { Tratam das Diretrizes Nacionais para Educação em Direitos } \\
\text { Humanos. }\end{array}$ \\
\hline Lei $n \cong 13.005$ de $25 / 06 / 2014$ & Institui o Plano Nacional de Educação. \\
\hline Lei no 10.049/2016 & $\begin{array}{l}\text { Institui o Plano Estadual de Educação do Rio Grande do } \\
\text { Norte. }\end{array}$ \\
\hline
\end{tabular}


O Plano Nacional de Educação em Direitos Humanos (PNEDH) ${ }^{7}$ foi um dos primeiros documentos nacionais a trabalhar estes direitos especificamente para a área da educação. Vale, assim, aprofundar a discussão de seu conteúdo. O PNEDH veio com a justificativa de que o Brasil passou por um processo de universalização e melhoria do ensino associado à significativa elevação da escolaridade da população. Tais elementos embasaram o fundamento de que era necessário direcionar esse crescimento promovendo a formação para o respeito à diversidade e às singularidades das pessoas (BRASIL, 2006).

O Plano, de forma geral, propõe a transversalidade da educação em direitos humanos nas políticas públicas, de modo a promover o desenvolvimento institucional e interinstitucional das ações previstas no PNEDH nos mais diversos setores da sociedade. Aborda a produção de informação e conhecimento, produção e divulgação de materiais, aponta ainda para a formação e capacitação de profissionais, assim como dispõe sobre os meios de avaliação e monitoramento (BRASIL, 2006).

O PNEDH representou um avanço na área de ensino de direitos humanos, pois torna o assunto parte do conteúdo do currículo escolar, principalmente a partir de 2009, com o Decreto n. 7.037/2009, que aprovou o Programa Nacional de Direitos Humanos - PNDH-3, efetivando a política (BRASIL, 2009).

Podemos citar no PNDH-3 a abordagem sobre educação e cultura em direitos humanos, com ênfase nos princípios democráticos, o respeito às diferentes crenças, à liberdade de culto e à garantia da laicidade do Estado como objetivo estratégico (BRASIL, 2009). Com relação as suas ações programáticas, o decreto estabelece o ensino da diversidade e história das religiões na rede pública de ensino, inclusive as derivadas de matriz africana, com enfoque no reconhecimento das diferenças culturais, promoção da tolerância e na asseveração da laicidade do Estado, promove também os direitos das pessoas com deficiência, garantindo a discussão sobre a acessibilidade, trazendo como ações programáticas o cumprimento do Decreto de Acessibilidade de n. 5.296/2004, e a garantia dos recursos didáticos e pedagógicos para atender às necessidades educativas especiais (BRASIL, 2009). Tais disposições legais figuram como ações afirmativas no sentido de difundir um ensino baseado na tolerância e no respeito às diferenças.

As orientações curriculares de 2006, tanto para as áreas de Linguagens, Códigos e Tecnologias como a de Ciências Humanas e suas Tecnologias, abordam a temática de forma sucinta e transversal, por meio da política de igualdades, no sentido de construir identidades que almejem e versem acerca do acesso igualitário aos bens sociais e culturais, coibindo todas as formas discriminatórias. Tais orientações sugerem a inserção de temas relacionados à temática em estudo, tais como: questão racial, etnocentrismo, preconceito, violência, sexualidade, gênero, meio ambiente, cidadania, direitos humanos, religião e religiosidade, movimentos sociais, meios de comunicação de massa, etc. (BRASIL, 2006).

Uma primeira versão do PNEDH foi formulada no ano de 2003, tendo sido efetivamente criado em 2006. Em 2009, com o Decreto 7.037/2009, é formalizada a terceira versão do Programa Nacional de Direitos Humanos (PNDH-3). É com a versão de 2009 que algumas efetivações da política vão se consolidando. 
As Diretrizes Curriculares Nacionais para a Educação Básica são decorrentes do parecer CNE/CEB n 7/2010, bem como da resolução n. 4, de 13 de julho de 2010. Tais diretrizes também abordam o ensino de direitos humanos em seu texto. $O$ parecer CNE/CEB no 7/2010, da Organização das Nações Unidas para a Educação, a Ciência e a Cultura (Unesco), assevera que a qualidade da educação corresponde diretamente a uma questão de direitos humanos, adquirindo caráter de direito fundamental (BRASIL, 2010). Vincular o ensino dessa temática à qualidade de ensino levanta diversos questionamentos acerca do que seria qualidade de ensino para a Unesco e para o Conselho Nacional de Educação no contexto da criação dessas diretrizes, não sendo possível precisar e fixar tal sentido.

Numa perspectiva de construção de uma sociedade mais democrática e solidária, novas demandas passam a ser inseridas no currículo, muitas delas relacionadas aos direitos humanos. Em 2012 foram criadas as Diretrizes Curriculares Nacionais para o Ensino Médio (DCNEM), embasadas por meio do parecer CNE/CEB n. 5/2011 e da resolução CNE/CEB n. 2/2012, carregando como pressupostos para o Ensino Médio de qualidade social, em seu artigo 50, os direitos humanos como um dos seus princípios norteadores.

$O$ referido parecer ressalta a obrigação de concretizar processos educacionais que instiguem a cidadania, o conhecimento dos direitos fundamentais, o reconhecimento e a valorização da diversidade étnica e cultural, de identidade de gênero, de orientação sexual, religiosa, entre outras, como formas de combate ao preconceito e à discriminação. A resolução CNE/CEB n. 2/2012 trouxe expressamente em seu artigo10, II, a educação em direitos humanos como temática obrigatória na organização curricular, devendo ser abordada de maneira transversal e integradamente, perpassando por todo o currículo, no âmbito dos demais componentes curriculares (BRASIL, 2012c).

As Diretrizes Nacionais para a Educação em Direitos Humanos originadas do parecer CNE/CP n. 8/2012, e Resolução CNE/CP n. 01/2012, de 30 de maio de 2012, foi outro documento de grande importância para o ensino do tema, carregando como princípios norteadores a dignidade humana, a igualdade de direitos, o reconhecimento e valorização das diferenças e das diversidades, a laicidade do Estado e a democracia na educação (BRASIL, 2012c). A respeito da forma de inserção dessa temática no currículo tais documentos trouxeram a transversalidade como uma de suas modalidades. A citada Resolução também dispõe acerca da obrigatoriedade da produção de materiais didáticos, fomenta a difusão de experiências eficazes relacionadas a estes direitos e determina a inclusão dessas discussões na formação docente.

A Lei n. 13.005, de 25/6/2014, institui o Plano Nacional de Educação com vigência de 10 anos. O referido Plano, em acordo com as demais legislações vigentes que tratam do ensino de direitos humanos, traz em suas diretrizes a promoção dos princípios do respeito a estes direitos, à diversidade e à sustentabilidade socioambiental.

Em âmbito estadual, o plano de educação do Rio Grande do Norte, instituído pela lei n. 10.049/2016, com prazo de vigência de 10 anos, traz os direitos humanos integrados ao ensino inclusivo de acordo com a previsão legalmente concebida. Em consonância com os demais textos oficiais apresenta como meta a efetivação de políticas 
afirmativas. Podemos ainda encontrar a busca por práticas de superação do racismo, do machismo, do sexismo e de toda forma de preconceito, no sentido de colaborar para a concretização de uma educação sem segregação (RIO..., 2016).

Conforme observado, algumas legislações apresentam as mesmas disposições legais, dando a entender que novas leis estão sendo criadas para garantir o que já estava positivado em nossa legislação pátria. Tal reprodução pode ser considerada não somente um reconhecimento da invisibilidade das ações voltadas para a efetivação destes direitos no contexto da prática, mas, em parte, pode também significar o fracasso de demandas que não conseguiram ser contempladas. Assim, alguns documentos relacionam essa temática a direitos voltados para construção de igualdades, sem considerar as diferenças e as disputas que ocorrem no preenchimento de sua significação.

Neste tópico foi possível reconhecer as expressões que inicialmente foram relacionadas aos direitos humanos, tais como: cidadania, tolerância, igualdade, diferença, inclusão e liberdade religiosa. Ao nos debruçarmos, porém, sobre os documentos específicos relacionados ao ensino destes direitos foram identificados outros termos, a exemplo de: diversidade, gênero, combate ao preconceito, discriminação, dignidade humana.

Os documentos antes relacionados serviram para nortear as discussões acerca do ensino dessa temática no Ensino Médio na sequência deste artigo, posto que tais legislações devam servir de referência para construção de práticas pedagógicas, abordagem de conteúdos em disciplinas, assim como na elaboração dos materiais didáticos. Tais normas, em diversos momentos, tentam fixar o conceito em questão, bem como deixam de considerar os diferentes contextos em que são trabalhados e suas possíveis ressignificações.

As legislações, apesar de representarem avanço na disputa para assegurar o ensino dessa temática, não garantem sua existência no contexto escolar. Neste sentido deve haver empenho em trabalhar essa temática como política em sala de aula, sendo necessário perceber como ocorre esse processo na escola. Assim, a inclusão de uma política de direitos humanos nos documentos oficiais não impede que sofra ressignificações no contexto da prática, mas uma vez associado a diversos indicadores que associam estes direitos com a qualidade de ensino e a consequente percepção de verbas, a probabilidade de tratá-lo em sala de aula aumenta consideravelmente.

\section{CONSIDERAÇÕES ACERCA DO ENSINO DE DIREITOS HUMANOS NO CONTEXTO DA PRÁTICA}

Oportuno mencionar que os discursos dos professores entrevistados auxiliaram na compreensão de como ocorre o ensino da temática no contexto da prática. Entendemos que os três tipos de contexto de Ball (2011), o contexto de influência, em que são definidos os conteúdos dos documentos; o contexto de produção de textos, quando são produzidos os documentos oficiais, e o contexto da prática, foco principal deste trabaIho, no qual são realizadas as ressignificações. Não são etapas e não estão estanques, eles trabalham de forma contínua e concomitante, de modo que enquanto os textos estão sendo produzidos, estão sujeitos a novas ressignificações. 
Nesse sentido, o objetivo deste trabalho consiste em perceber como se dá o ensino de direitos humanos nas escolas públicas de Ensino Médio no contexto da prática, considerando os diversos filtros e ressignificações pelas quais perpassa essa temática.

\section{Da Acepção dos Direitos Humanos sob a Ótica dos Professores}

Primeiramente buscamos entender o que os professores entrevistados concebiam por direitos humanos, sendo este um dos elementos a ser considerado ao analisar a abordagem do assunto em sala de aula. Procuramos ainda perceber o que estava sendo feito em nome destes direitos e sua relação com as disciplinas. Dois dos entrevistados, A e B, apresentaram uma visão associada ao conceito de cidadania; essa associação remete a diversos documentos da década de 90 já comentados neste texto, tendo apresentado resquícios nas legislações das décadas seguintes. Da área de ensino, os PCNs podem ser utilizados como exemplo, tendo em vista que a terminologia cidadania estava relacionada ao sentido de direitos humanos. ${ }^{8}$

A compreensão do termo cidadania nos PCNs recebe influência da ótica universalista que, mesmo reconhecendo as diferenças, quando faz referência a estilos de vida não convencionais, destaca a busca pela distribuição igualitária das conquistas sociais. Essa perspectiva de dissolução das desigualdades apaga as disputas e mostra estar inserida em uma percepção de sociedade fixa e estruturada. Desse modo, a associação do vocábulo cidadania, sendo compreendido como sinônimo de direitos humanos traduzida no documento revela a força de grupos que buscavam hegemonizar a visão fixa e universalista de tais direitos e que tal perspectiva continua a ser reproduzida, conforme discursos dos professores.

Segundo Ramos (2011), estes direitos devem ser compreendidos para além do conceito liberal de campo de alcance e consenso, propondo que ele seja entendido como arena de expressão da diferença, do dissenso. A autora destaca ainda o conceito de abordagem agonística, fazendo uma relação a respeito da abordagem destes direitos partindo da afirmação da diferença e não da universalidade. Essa perspectiva não evita o embate pelo apagamento do outro que ameaça, mas reconhece a equivalência do adversário.

\footnotetext{
${ }^{8}$ A cidadania só pode ser entendida plenamente na medida em que possa ser traduzida em reconhecimento dos direitos humanos, prática da igualdade de acesso aos bens naturais e culturais, atitude tolerante e protagonismo na luta pela sociedade democrática. Sem a consciência de direitos e deveres individuais e coletivos, sem a sede de uma justiça que distribua de modo equânime o que foi produzido socialmente, sem a tolerância a respeito de opiniões e estilos de vida "não convencionais" e, sobretudo, sem o engajamento concreto na busca por uma sociedade democrática, não é possível de nenhum modo que se imagine o exercício pleno da cidadania. É o aspecto que poderíamos chamar de participação democrática.

BRASIL. Ministério da Educação. Secretaria de Educação Média e Tecnológica. Parâmetros Curriculares Nacionais Ensino Médio: Parte IV. Brasília: MEC; SEMTEC, 2000. Disponível em: <http://portal.mec.gov.br/seb/arquivos/pdf/ cienciah.pdf>. Acesso em: 25 jun. 2016.
} 
Nesse sentido, os referidos parâmetros sugerem práticas pedagógicas para abordar a temática em sala de aula, de modo que o aluno possa utilizar o contexto dinâmico da prática em que está inserido para problematizar diversas questões, assim como construir uma visão crítica e transformadora a respeito dos direitos humanos ${ }^{9}$ de modo a seguir além dessas fixações.

O terceiro entrevistado, professor $\mathrm{C}$, apresenta visão mais abrangente e problematizada do assunto questionado ao tratar de direitos humanos de modo a englobar a defesa de direitos de grupos variados: mulheres, crianças e homossexuais.

Hoje um tema que nós devemos tratar com atenção, com relação aos direitos humanos, é questão da homofobia (...). Então, nós temos também, no Brasil, quando se fala da questão da mulher, a violência doméstica, é algo realmente muito difícil de se mudar. A violência contra os menores. Inclusive há um debate se a idade penal deve ser diminuída (professor C).

A visão exposta pelo professor aproxima-se de uma acepção mais aberta dos direitos humanos exemplificando diversos sujeitos, de modo a perceber que estes sujeitos não são fixos, e que sofrem diversas influências conforme os contextos em que estão inseridos, assim como se aproximam dos discursos oficiais demonstrando a influência do contexto na prática da sala de aula.

Ainda a respeito do sentido de direitos humanos, em outro trecho da entrevista destacou ainda a existência do preconceito da sociedade.

É que nós sempre ouvimos dizer que os direitos humanos só servem para proteger criminoso. Que não serve pra proteger o cidadão de bem. Eu acho que o conceito, quando se trabalha nesse aspecto, é errado (professor C).

O preconceito anteriormente mencionado trata-se da fixação de um sentido que não contempla os diversos contextos e situações que podem ser elencados dentro dos direitos humanos. Esta menção não somente evidencia, mas confirma que os preconceitos acerca destes direitos ainda estão presentes na sociedade e nos mais diversos ambientes, assim como na escola e demais contextos relacionais. Nas últimas décadas, apesar do grande avanço nas lutas por estes direitos, consolidou-se um preconceito, em uma parcela significativa da sociedade, acerca das pessoas que defendem tais direitos sob a alegação de que estariam advogando em prol dos criminosos. Tal preconceito pode estar associado à ausência de conhecimento a respeito do assunto somado a uma definição prefixada pela sociedade atual de forma cultural e discursiva. ${ }^{10}$ Nessa pers-

\footnotetext{
${ }^{9}$ A contextualização do sistema social brasileiro, estruturado em classes sociais, excludente e concentrador de renda e de poder, vai permitir a elaboração de variadas atividades pedagógicas. O aluno poderá, por exemplo, recolher do seu entorno diversos exemplos de exclusão social, econômica e política: histórias de vida, fotografias, vídeos e filmes, matérias jornalísticas etc. (...) O professor e o aluno, entretanto, poderão avançar ainda mais, se forem criadas oportunidades de atuação cidadã, isto é, se o aluno puder protagonizar a mudança, mesmo que pequena, viabilizando o exercício da cidadania dentro ou fora da escola

BRASIL. Ministério da Educação. Secretaria de Educação Média e Tecnológica. Parâmetros Curriculares Nacionais Ensino Médio: Parte IV. Brasília: MEC; SEMTEC, 2000. Disponível em: <http://portal.mec.gov.br/seb/arquivos/pdf/ cienciah.pdf>. Acesso em: 25 jun. 2016.

${ }^{10} \mathrm{O}$ autor Dalmo Abreu Dallari assevera que a origem do referido preconceito surgiu na época da ditadura, que foi difundido para justificar e desvirtuar o foco das violações praticadas, diante das diversas denúncias dos defensores dos direitos humanos. DALLARI, Dalmo Abreu. In: O preconceito. São Paulo, 1997. Disponível em: <http://www. defendebrasil.org.br/novo/img/pdf/preconceito_.pdf>. Acesso em: 2 jul. 2016.
} 
pectiva, o rótulo atribuído aos direitos humanos, no sentido de macular sua finalidade, trata-se, na verdade, de uma fixação de sentido, demonstra a disputa na qual estão inseridos, com a educação constituindo uma ferramenta para problematizar os conceitos predefinidos que muitas vezes são apenas assimilados pelas pessoas, sem qualquer análise crítica sobre o assunto.

Sob outra ótica também foi inserida nessas respostas a inerência dos direitos humanos, revelando uma forte influência de uma percepção fixa e universal desse conceito nas falas dos professores.

Tais respostas indicam também a hegemonia desse discurso, porém essa hegemonia é precária, uma vez que não é eterna, podendo mudar conforme as negociações que são operadas dentro dos diversos contextos. Com relação à inerência destes direitos pode-se afirmar que, partindo de um viés pós-estruturalista, tal visão não pode ser fixa, tendo em vista a dinamicidade das ações humanas e inúmeras possibilidades de ressignificações (LOPES; MACEDO, 2011b).

Compartilhamos do entendimento de Ramos (2011) quando afirma que os direitos humanos foram construídos seguindo a ótica das sociedades ocidentais, excluindo as demais sociedades, fazendo-se necessário perceber que a visão em questão está em constante processo de disputa, comportando diversas demandas pela hegemonia.

Conforme mencionado anteriormente, compreender os direitos humanos de forma universal significa fixar os sujeitos, suas diferentes demandas, e entender a possibilidade de ausência de demandas e disputas, de maneira que não corresponde à realidade.

\section{Da Visão dos Professores Acerca dos Direitos Humanos na Prática Interdisciplinar}

Outro ponto estudado foi a relação entre o conteúdo das disciplinas e a abordagem dos direitos humanos. Nesse sentido foi solicitado aos professores que apontassem como as disciplinas do Ensino Médio podem trabalhar em conjunto com essa temática. Os resultados obtidos por intermédio dos professores entrevistados apontaram como alguns exemplos de associação, na área da Biologia com a temática, quando relacionados a questões de gênero, ao direito dos indígenas e outras associações com conteúdos relacionados à Religião e Sociologia.

$O$ entrevistado A mencionou que:

A minha. Ela perpassa muito essa questão de direitos humanos. A questão biológica tem muitas questões que relacionadas, como, por exemplo: a reprodução humana, na questão de gêneros, onde tem uns grupos que defendem os direitos deles, mas outros já rejeitam isso, acham que não é biologicamente normal. (...) (professor A).

Tal afirmação revela a possibilidade de abordagem deste assunto de forma interdisciplinar e transversal, de modo que não fixa o sentido, mas que relaciona a discussão conforme a aproximação com a temática que está sendo trabalhada em sala de aula. Em outros trechos da entrevista o entrevistado B esclareceu o papel ativo dos alunos que, em diversas oportunidades, trazem questionamentos e problematizações a serem discutidas, relacionando os direitos humanos com a matéria trabalhada em sala de aula. 
Sempre acontece discussões quando há um problema que chama atenção nacionalmente, né. Esse tema sempre volta para a sala de aula, sempre há uma discussão, até mesmo os alunos, eles discutem isso, mesmo que o professor não puxe essa discussão. Muitas vezes eles iniciam (professor B).

Com relação à disciplina de História, o entrevistado $\mathrm{C}$ asseverou a possibilidade de associação, bem como mencionou que o conteúdo de direitos humanos apresenta melhor possibilidade de abordagem nas disciplinas da área de Ciências Humanas, e um deles acredita que a abordagem deva ser mais aprofundada de modo que seja construída uma disciplina com essa finalidade. O professor B informou que não existia a abordagem interdisciplinar do ensino dessa temática, resumindo a abordagem do assunto por meio de palestras.

Palestras nós temos sim. Agora projetos mesmo, direcionados para os direitos humanos, não. Que eu conheça não (professor B).

A respeito da abordagem interdisciplinar a pesquisa revelou a falta de conhecimento acerca da interdisciplinaridade por parte dos professores, uma vez que trabalhar de forma interdisciplinar corresponde a trabalhar a comunicação entre as disciplinas, de modo que uma não se sobreponha a outra (SILVA; TAVARES, 2011). O ensino interdisciplinar promove a integração de conteúdos sem criar uma nova disciplina. Nessa abordagem os direitos humanos também podem ser discutidos de forma contextual, de modo a ampliar as formas de problematização dos conteúdos.

Os exemplos citados nas entrevistas revelam aproximações com a interdisciplinaridade por meio da contextualização, tal como justaposição de conteúdos, porém não traz um exemplo de interdisciplinaridade. ${ }^{11} \mathrm{~A}$ ausência da interdisciplinaridade, todavia, não deve ser apontada como falha, tendo em vista que abordar a temática em palestras pode ser considerada uma difusão de conteúdo, e embora saia da interdisciplinaridade, tendo em vista que separa o assunto dos demais, demonstra que o assunto está sendo discutido no contexto da prática.

O reconhecimento dos direitos humanos como política interfere e influencia, conforme o contexto de influência de Ball (2011), na inserção como conteúdo nos materiais didáticos de modo a possibilitar a discussão em sala de aula. Ademais, existe a possibilidade de o professor estar trabalhando o assunto em sala de aula sem que tenha plena consciência do ato, seja analisando um tópico trazido no material didático, seja abordando um assunto relacionado a estes direitos. Cabe destacar a necessidade de valorizar e compreender o que se faz em prol da discussão dessa questão em sala de aula.

O currículo, assim como os direitos humanos, num viés pós-estruturalista é considerado um significante vazio a ser preenchido de acordo com o contexto e as disputas que envolvem a sua fixação contingente. A inserção como conteúdo no currículo revela a tentativa de direcionar o leitor, reconhecendo a inoperância da apreensão plena (LOPES; MACEDO, 2011a).

\footnotetext{
${ }^{11} \mathrm{O}$ trabalho interdisciplinar por meio de temáticas parece ser um caminho encontrado pelos professores; o risco, porém, está na mera justaposição ou sobreposição dos aqui denominados "conteúdos disciplinar" e "auxiliar", sem alguma articulação significativa entre eles. SILVA, Aida Monteiro; TAVARES, Celma. A formação cidadã no Ensino Médio. São Paulo: Cortez, 2012.
} 
Os direitos humanos compreendidos como significante vazio podem ser preenchidos por diversas problemáticas a serem discutidas em sala de aula. A formação de professores pode ser um dos elementos que auxiliam no processo de abordagem do assunto com o objetivo de perceber os múltiplos sentidos que podem ser atribuídos ao tema em questão.

\section{A Prática dos Direitos Humanos na Escola Numa Abordagem Interdisciplinar}

O terceiro ponto em discussão buscou compreender de que forma a escola trabaIha direitos humanos no Ensino Médio. O sentido de tal questionamento é buscar encontrar meios de dissolver a dicotomia entre política e prática, possibilitando uma visão mais abrangente da escola, de modo a entendê-la como mais que um local de efetivação de políticas, mas um lugar diretamente influenciado pelos contextos, pelas disputas que envolvem a própria escola, governo, comunidade local, que pode abranger currículos, bem como demandas relacionadas ao ensino dessa temática (SANTOS, 2016).

Os resultados apresentaram como resposta predominante o uso de palestras como instrumento de debate e difusão para o ensino dessa temática. Ainda na mesma questão verificou-se outra categoria relacionada ao papel questionador dos alunos, que muitas vezes instigam o debate por meio de seus comentários.

Outro aspecto verificado foi uma visão fortemente disciplinar do tema, tendo em vista que dois deles, A e B, avaliaram a ausência de disciplina e sistematização do ensino de direitos humanos na escola como obstáculo.

Já o professor A destacou a ausência de ligação do conteúdo e com os direitos humanos.

Não está coincidindo a disciplina de direito com o conteúdo que nós estamos ensinando, tem que sair às vezes do conteúdo e puxar outra coisa que tenha a ver com o direito que está sendo discutido, o de gênero aí em alguns anos não tem nada a ver o conteúdo com a questão de gênero, mas devido à polêmica do que está acontecendo, a gente puxa e começa a discutir dentro da Biologia o que é que é direito? O motivo de não respeitar o outro, o que é a que a Biologia tem a ver com isso? Se o gênero não é biológico, mas só o fato de não ser biológico não significa dizer que a pessoa não tenha direito. A ser daquela forma, a ser daquele jeito. As diferenças existem. A cultura também interfere nisso. Aí que entra a questão cultural, social e econômica (professor A).

Tal posicionamento indica a necessidade de trabalhar mais o assunto com os professores, igualmente uma formação voltada para essa finalidade, de modo que o referido professor possa trabalhar melhor esses conteúdos de forma a relacionar com o teor de sua disciplina. As temáticas que abordam as questões de gênero estão totalmente relacionadas às questões de direitos humanos e o entrevistado revela que percebe essa associação, mas que necessita de maior embasamento para uma articulação mais densa em sala de aula.

A visão disciplinar da professora B inviabiliza a interdisciplinaridade, haja vista que promove a hiper/superespecialização de saberes, de modo a tratar as disciplinas como bolhas impermeáveis, bem como tende a simplificar os conceitos (SILVA; TAVARES, 2012). 
Eu já tive uma experiência nesse sentido, há uns 3 ou 4 anos atrás eu trabalhei a Declaração dos Direitos Humanos na sala de aula com os alunos. Nesse tempo que eu estou aqui, que eu lembre, de forma sistematizada, só a minha disciplina que trabalhou.

Esta fala revela o interesse por uma disciplina sobre o ensino de direitos humanos no Ensino Médio, haja vista que um dos entrevistados demonstrou, em vários trechos da entrevista, um posicionamento no sentido de tratar o assunto por meio de uma disciplina específica.

A criação de uma nova disciplina, no entanto, não pode ser considerada uma fórmula mágica com a qual os questionamentos se encerram de forma instantânea. Incluir nova disciplina implica tratar de vários aspectos em disputa, tais como: discussões acerca da formação docente nessa área, e também levanta debates se apenas profissionais da área jurídica poderiam ministrar aulas sobre direitos humanos.

Em diversos momentos o órgão público tenta qualificar docentes de outras áreas no sentido de evitar o comprometimento de recursos financeiros com a contratação de novos professores. Outro questionamento a ser levantado é a questão do tempo a ser trabalhado em sala de aula. O referido tempo é constantemente objeto de disputas por parte de disciplinas que buscam ascender hegemonicamente ou consolidar as suas hegemonias por meio do aumento de sua carga horária.

A criação de nova disciplina com carga horária diferenciada certamente implicará a redução da carga horária de outra disciplina, de modo que gerará diversos conflitos que irão obstar a sua realização. Ainda dentro dessa perspectiva outro ponto que merece ser abordado é o conteúdo e de que maneira ele será constituído, à medida que as discussões relacionadas aos direitos humanos estão em constante disputa por sua significação. Desse modo, construir uma nova disciplina não se mostra tarefa fácil, tendo em vista que são frutos de diversas lutas e negociações.

Outro ponto a ser considerado é que no contexto de influência e no contexto de produção de textos, as políticas influenciam os conteúdos das disciplinas, bem como dos materiais didáticos que, por sua vez, passam por inúmeras ressignificações, que muitas vezes formam híbridos. Nesse processo são inseridos os conteúdos de direitos humanos dentro dos materiais didáticos, de modo que possibilitam aos professores promover sua própria ressignificação.

Nesse sentido entendemos que, embora ocorra certa rejeição por trabalhar os direitos humanos de forma interdisciplinar, os professores, muitas vezes, já fazem isso ao responder aos questionamentos dos alunos, ao trabalhar o material didático em sala de aula.

As afirmações dos professores cooperam também para a compreensão de que os conteúdos das disciplinas estão em constante disputa, seja para trabalhar a temática de direitos humanos de forma transversal, conforme determinam os documentos oficiais, ou mediante a criação de uma nova disciplina conforme desejo de parte dos docentes entrevistados. 


\section{CONSIDERAÇÕES FINAIS}

O presente artigo buscou analisar como se dá a relação entre os instrumentos legais e o ensino de direitos humanos nas escolas públicas de Ensino Médio no contexto da prática. Para isso foi realizando inicialmente um percurso histórico dos principais instrumentos legais, tendo ainda como objetivo estudar suas principais acepções e eleger contingencialmente uma para servir de referência para o texto. Ao mesmo tempo foram identificadas palavras relacionadas ao conteúdo destes direitos que servirão de base para novas pesquisas na área.

Diante de todos os documentos analisados percebemos que os direitos humanos deram um salto de difusão por meio da criação de diversos documentos oficiais nas últimas décadas, porém ainda há muito a ser trabalhado no que se refere especificamente ao ensino destes direitos, haja vista que a instituições de leis não é o suficiente para que a temática seja trabalhada em sala de aula.

Partindo de uma aproximação pós-estruturalista utilizamos como referência o sentido de direitos humanos como um significante vazio utilizando como referência Laclau (2005) e Lopes e Macedo (2011b). Esse preenchimento é contingente e ocorre de acordo com o contexto, estando sujeito a diversas e constantes negociações. Nesse sentido foram utilizados os contextos de Ball e Bowe (1998) para perceber o que estava sendo feito em nome destes direitos no contexto da prática.

Buscamos ainda entender de que forma os docentes respondem às exigências e expectativas propostas nos documentos oficiais relacionados ao ensino dessa temática, principalmente no que respeita ao seu caráter interdisciplinar, bem como em relação à operacionalização daqueles conteúdos que são considerados referentes aos direitos humanos.

Conforme estes documentos oficiais estudados o ensino de direitos humanos deve ser inserido num contexto interdisciplinar do processo de aquisição de conhecimento, tendo em vista a sua relação com diferentes campos de saberes e de práticas pedagógicas a serem trabalhadas na escola no sentido de promover a busca pela justiça e igualdade social. A valorização e promoção destes direitos mediante a discussão de temas relativos às questões de gênero, etnia, religião, pessoas com deficiência, bem como práticas voltadas para a igualdade, para o combate a todas as formas de preconceito e violência sob todas as formas, são elementos a serem considerados no Projeto Político-Pedagógico das unidades escolares que ofertam o Ensino Médio nos termos das diretrizes nacionais.

A interdisciplinaridade no ensino dessa temática pode ser utilizada como ferramenta para que o professor tenha a liberdade de abordar a questão de forma interligada, mas ao mesmo tempo independente, porém ainda que a interdisciplinaridade não seja encontrada, devemos considerar as ressignificações realizadas em razão do ensino de direitos humanos.

No caso em estudo, as falas dos professores apresentaram visão extremamente disciplinar, mas todos reproduziram os discursos oficiais acerca da importância do ensino dessa temática na escola, bem como relataram casos em que os temas foram discutidos em sala de aula, e a explanação por meio de palestras, demonstrando que ainda 
que não seja de forma interdisciplinar as questões que envolvem os direitos humanos são discutidas e estão sempre presentes no cotidiano dos alunos, seja mediante a contextualização, justaposição de conteúdos, ou mesmo que não seja de forma intencional.

Os resultados da parte empírica demonstram que embora existam discussões a respeito da abordagem dessas questões, quer seja em forma de palestras, ou ainda de questionamentos dos próprios alunos, tal ponto está em constante disputa, ora por resistência por parte dos alunos, ora por resistência e falta de qualificação de professores, sendo construídos híbridos de acordo com cada contexto.

Outro aspecto identificado nas entrevistas foi um forte entendimento no sentido de transformar os direitos humanos numa disciplina, porém tal posicionamento necessita de reflexão das possíveis implicações para a inserção de uma nova disciplina na grade curricular do Ensino Médio, sendo de difícil efetivação. Tal posicionamento dos professores indica a necessidade de instituição de políticas de educação no sentido de formar permanentemente os professores nessa área de conhecimento, com intuito de promover a possibilidade de discussão do assunto em sala de aula.

Devemos compreender que existem diferentes contextos (Ball, 2011), bem como as disposições dos documentos oficiais são passíveis de infinitas ressignificações, seja no currículo, material didático, ou até em sala de aula, mas isso não significa que os direitos humanos não estão sendo trabalhados. A incerteza faz parte desse contexto que está em constante disputa e que, a todo o momento, pode sofrer ressignificações.

De modo geral, este levantamento aponta que os direitos humanos apresentam a hegemonia de uma perspectiva fixa e universalista. Entender o significado destes direitos como significante vazio coopera para noção das disputas que envolvem o sentido adotado, bem como deve ser refletido levando em consideração as inúmeras ressignificações que sofre, nos mais diversos contextos, inclusive no contexto da prática.

\section{REFERÊNCIAS}

BALL, Stephen J. Políticas educacionais: questões e dilemas. São Paulo: Cortez, 2011.

BALL, Stephen J.; BOWE, Richard. El curriculum nacional y su "puesta en práctica": el papel de los departamentos de materias o asignaturas. Revista de Estudios del Curriculum, v. 1, n. 2, p. 105-131, 1998.

BALL, Stephen J.; MAINARDES, Jefferson (Org.). Políticas educacionais: questões e dilemas. São Paulo: Cortez, 2011.

BARBOSA, Ruy. Oração aos moços. 10. ed. Rio de Janeiro: Forense, 1976. p. 25.

BRASIL. Constituição 1988. Brasília: Senado, 1988.

Lei de Diretrizes e Bases da Educação: Lei no 9.394/96 - 24 de dez. 1996. Estabelece as diretrizes e bases da educação nacional. Brasília, 1998.

Comitê Nacional de Educação em Direitos Humanos. Plano Nacional de Educação em Direitos Humanos: 2006. Comitê Nacional de Educação em Direitos Humanos. Brasília: Secretaria Especial dos Direitos Humanos; Ministério da Educação, Ministério da Justiça; Unesco, 2006. 56 p.

Decreto no 7.037 de 21 de dezembro de 2009. Aprova o Programa Nacional de Direitos Humanos

- PNDH-3 e dá outras providências. Brasília, Diário Oficial da União, 22 dez. 2009.

Secretaria de Direitos Humanos da Presidência da República. Programa Nacional de Direitos Hu-

manos (PNDH-3). Secretaria Especial dos Direitos Humanos da Presidência da República. Brasília: SEDH/ PR, 2010.

Parecer CNE/CP no 8/2012. Diretrizes Nacionais para a Educação em Direitos Humanos. Brasília: MEC; CNE, 2012a.

Resolução CNE/CP no 01/2012, de 30 de maio de 2012. Estabelece Diretrizes Nacionais para a Educação em Direitos Humanos. Brasília: MEC; CNE, 2012b. 
BRASIL. Conselho Nacional de Educação - Câmara de Educação Básica. Diretrizes Curriculares Nacionais para o Ensino Médio. Parecer CNE/CEB n. 5/2011. Brasília, 2011. DOU de 24 de jan. 2012c, Seção 1, p. 10.

Ministério da Educação. Secretaria de Educação Média e Tecnológica. Parâmetros Curriculares Nacionais Ensino Médio: Partes I a IV. Brasília: MEC; Semtec, 2000. Disponível em: <http://portal.mec.gov. br/seb/arquivos/pdf/baseslegais.pdf>. Acesso em: 25 jun. 2016.

. Ministério da Educação. PCN+ Orientações Educacionais Complementares aos Parâmetros Curriculares Nacionais - Brasília: MEC; SEMT, 2002a. Disponível em: <http://portal.mec.gov.br/seb/arquivos/ pdf/CienciasNatureza.pdf>. Acesso em: 25 jun. 2016.

CHAUÍ, Marilena; SANTOS, Boaventura de Sousa. Direitos humanos, democracia e desenvolvimento. São Paulo: Cortez, 2013.

DALLARI, Dalmo Abreu. In: O preconceito. São Paulo, 1997. Acesso em: 2 jul. 2016. Disponível em: <http:// www.defendebrasil.org.br/novo/img/pdf/preconceito_.pdf>.

LACLAU, Ernesto. La Razón Populista. Buenos Aires: Fondo de Cultura Econômica, 2005.

Inclusão, exclusão e a construção de identidades. In: AMARAL JÚNIOR, A; BURITY, J. A. Inclusão social, identidade e diferença: perspectivas pós-estruturalistas de análise social. São Paulo: Ed. Annablume, 2006.

LOPES, Alice Casimiro; MACEDO, Elizabeth. Contribuições de Stephen Ball para o estudo de políticas de currículo. In: Políticas educacionais: questões e dilemas. São Paulo: Cortez, 2011a.

(Org.). Teorias de currículo. São Paulo: Cortez, 2011b.

MATHEUS, Danielle. Políticas de currículo em Niterói, Rio de Janeiro: o contexto da prática. 2009. 166p. Dissertação (Mestrado) - UERJ, Rio de Janeiro, 2009.

RAMOS, Aura Helena. O lugar da diferença no currículo em direitos humanos. Rio de Janeiro: Ed. Faperj, 2011.

RIO GRANDE DO NORTE. Lei no 10.049 de 27 de janeiro de 2016. Aprova o Plano Estadual de Educação do Rio Grande do Norte (2015-2025) e dá outras providências. Natal/RN, 27 jan. 2016.

SANTOS, Jean Mac Cole Tavares; OLIVEIRA, Marcia Betania de. Políticas curriculares no Ensino Médio: ressignificações no contexto escolar. Revista Currículo sem Fronteiras, v. 13, n. 3, p. 497-513, set./dez. 2013.

SANTOS, Jean Mac Cole Tavares. Políticas de currículo: educação de qualidade em contextos. In: Reinvenções do currículo. Sentidos e reconfigurações do contexto escolar. Fortaleza: Ed. UFC, 2016.

SANTOS, Boaventura de Sousa. Reconhecer para libertar: os caminhos do cosmopolitanismo multicultural. Introdução: para ampliar o cânone do reconhecimento, da diferença e da igualdade. Rio de Janeiro: Civilização Brasileira, 2003.

SANTOS, Boaventura de Sousa; CHAUI, Marilena. Direitos humanos, democracia e desenvolvimento. São Paulo: Cortez, 2013.

SILVA, Aida Monteiro; TAVARES, Celma. A formação cidadã no Ensino Médio. São Paulo: Cortez, 2012. 